\title{
O comentário elogiativo nas redes sociais: estratégias de cortesia valorizadora
}

\author{
Isabel Roboredo Seara ${ }^{1} \&$ Ana Lúcia Tinoco Cabral ${ }^{2}$ \\ ${ }^{1}$ Universidade Aberta e CLUNL / ${ }^{2}$ Universidade Cruzeiro do Sul - São Paulo
}

\begin{abstract}
:
In recent years, the social networking website Facebook has become a referential online area for the development and strengthening of social bonds, of pre-existing social relationships from offline daily life (LAMOE et al 2006). Assuming that social networks are collective and collaborative spaces of communication and information exchange, which have changed the way thousands of people communicate to each other, and being Facebook the most widespread networking website (KREUTZ 2009), it becomes a fruitful field to the research of verbal interactions. However, there is a new epistemological positioning which endorses the necessity to rethink the description of the Facebook network, not only as a platform of communication, but also as a complex discursive environment, in which notions of identity, intimacy and social-affective bonds are important issues to be discussed (EMERIT-BIBIÉ L., 2015). Grounded on the dialogical design of language (BAKHTIN, 2003) and being engaged on verbal interactions researches, the article highlights the dialogical dimension which underlies the sociability especially built via "comments" mode - a discursive, social and public space which allows the construction and management of someone's own identity and alterity. Through a pragmatic approach, we reflect upon meaningful speech acts - particularly the ones related to congratulations, compliments and other laudatory acts - as an expression of support and encouragement, in which interlocutors resort to discursive strategies that value the positive and cordial face of others. The theoretical framework favors studies related to the verbal politeness, namely the ones of Brown \& Levinson (1987); Kerbrat-Orecchioni (2001 e 2004), Araújo Carreira (1997) and Vivas Márquez (2014).
\end{abstract}

Keywords: comity; meaningful speech acts; social networks; verbal interaction; comments; laudatory acts. Palavras-chave: cortesia; atos de fala expressivos; redes sociais; interação verbal; comentário; atos laudatórios.

\section{Introdução}

Na conclusão da segunda edição da obra consagrada à linguagem da internet, David Crystal (2006) sublinha que estamos a viver a maior revolução da linguagem e que a linguagem da Internet (Netspeak) poderá tornar-se a norma num mundo em que os indivíduos interagem preferencialmente através de um suporte tecnológico, mais do que face-a-face. Urge, pois, estabelecer pontes entre campos disciplinares distintos, vastos e promissores, que muito nos podem ajudar a compreender algumas dessas novas práticas verbais e sociais, desde a comunicação mediada por computador (CMC), à sociologia, às ciências da linguagem, nomeadamente à análise do discurso e à pragmática. 
O ritmo das mudanças decorrentes das inovações tecnológicas, a célere transição dos meios de comunicação eletrónicos, a revolução digital, configuram um fenómeno de tão elevada repercussão e amplitude, que importa proceder a questionamentos ontológicos e reflexivos sobre a adequação e a eficácia dos diferentes meios e repensar e redefinir o papel e o estatuto que podem assumir no âmbito das interações verbais e sociais.

Numa sociedade em que se assiste a uma crescente exposição pública do indivíduo, há uma tendência para uma visibilidade compulsiva. A fronteira entre público e privado é cada vez mais ténue e as redes sociais, como refere Raquel Recuero (2009: 103), diferenciam-se das outras formas de CMC pelo modo como permitem a visibilidade e a articulação, a manutenção dos laços sociais estabelecidos no espaço off-line. Tomamos como exemplo a rede Facebook.

A rede Facebook foi fundada em 2004 pelo americano Mark Zuckerberg e foi concebida para ser utilizada somente entre alunos da Universidade de Harvard, nos Estados Unidos. O projeto, porém, alcançou tanto sucesso que, em pouco tempo, a ideia inicial foi adaptada e expandiu-se por todo o mundo. Na base da criação da rede facebook está uma única intenção: de incentivar a interação entre utilizadores: "Millions of people use Facebook everyday to keep up with friends, upload an unlimited number of photos, share inks and videos, and learn more about the people they meet"1.

À rede Facebook estão subjacentes três objetivos: partilhar informação; influenciar semelhantes; manter-se informado. Essas três características estão intimamente relacionadas com o pensamento de Bakthin sobre o dialogismo, sendo este "compreendido como uma das formas composicionais do discurso" (Bakthin, 1979:346), em que a relação dialógica é estabelecida entre enunciados, na comunicação verbal. Para Bakthin, trata-se de um fenómeno próprio a todo discurso vivo, considerando que toda a enunciação possui a propriedade dialógica, ou seja, de estar ao serviço de um propósito interativo.

O propósito interativo encontra-se, para além dos objetivos do Facebook, na própria definição que a rede apresenta de si aos potenciais utilizadores, conforme a própria explicação que consta oficialmente na página Facebook:

\footnotetext{
${ }^{1} \mathrm{Cf}$. https://www.facebook.com/pg/FacebookAU/about/) portal da rede social facebook, acedida em setembro de 2016. 
Facebook is a social utility that helps people better understand the world around them. Facebook develops technologies that faciltate the spread of information trough social networks allowing people to share information online the same way they do it in the real world. Anyone can sign up for Facebook and interact with the people they know in a trusted environment. Facebook is a part of millions of people's lives all around the world”." (Facebook.com Official Statistics Page).

Podemos, assim, questionar: que interações comunicativas são predominantes? Para sustentar este nosso questionamento, o contributo teórico de Erving Goffman é determinante, na medida em que estamos face a análises da interações simbólicas inspiradas na representação teatral, na dramaturgia. Na sua obra The Presentation of Self in Everyday Life, o sociólogo enfatiza não só a causa do comportamento humano, mas também o seu contexto. (Goffman, 1993: 9).

Nas redes sociais, acontece igualmente o que Goffman designa "idealização", ou seja, o desempenho de cada indivíduo que tende a integrar e ilustrar os "valores oficialmente reconhecidos pela sociedade"(Goffman, 1993: 49-50) para os atores proporcionarem aos interlocutores uma impressão idealizada. A rede social configura, pois, um espaço onde os interlocutores estão não apenas expostos a discursos, mas onde igualmente são produtores. Trata-se, como bem observou Devellotte (1996, 2006), de um "espaço de exposição discursiva", ou seja, um «environnement constitué des énoncés, textes ou discours, auquel est exposé tout acteur placé dans un espace social donné » (Moirand, 2002: 258) e um espaço de produção discursiva.

Para a análise das interações na rede social, importa também convocar alguns instrumentos descritos por Herring, da denominada Análise da comunicação mediada por computador, «toute analyse de comportement en ligne qui se fonde sur des observations empiriques, textuelles est de l'analyse de discours médié par ordinateur » (Herring, 2004: 2), em que os dados devem ser produzidos natural e espontaneamente, recolhidos pelo investigador a partir de arquivos online. A rede Facebook oferece dados dessa natureza.

A contribuição na rede de facebook é ordenada e determinada: a interface hierarquiza as contribuições que podem ser iniciativas ou reativas. A interface pode ser igualmente multimodal, na medida em que o utilizador pode publicar uma mensagem escrita mas 
simultaneamente estabelecer uma ligação para um site, um vídeo, uma fotografia. A interação com os outros membros é a priori assíncrona, embora o tempo de reação possa ser tão ínfimo que cria o que se designa pela ilusão da sincronia. O discurso é multi-endereçado ao conjunto de pessoas, e as contribuições são geralmente curtas, próximas do microblogue, sem, no entanto, serem constrangidas automaticamente, como é o caso do twitter. Por esta razão, justifica-se um estudo dos comentários elogiativos no Facebook, a fim de verificar o caráter de idealização (Goffman, 1993) que se encontra nas contribuições dos participantes. Selecionamos, para as análises neste estudo, 178 comentários.

O presente trabalho tem por objetivo recensear e analisar as estratégias linguísticodiscursivas que estão na base da cortesia valorizadora presente nos comentários elogiativos a fim de verificar de que forma o espaço discursivo comentário no Facebook permite a construção e a gestão da própria identidade e do outro.

\section{O espaço discursivo comentário e a cortesia valorizadora}

Inscrevemos nosso trabalho no campo dos estudos da Análise do Discurso (escola francesa, doravante designada por $\mathrm{AD}$ ), da Análise Conversacional, de inspiração etnometodológica, da microssociologia goffmaniana que inspirou a linguística interacionista e, ainda, da pragmática.

Desse ponto de vista teórico, o comentário Facebook configura, pois, um espaço discursivo, social, público que permite a construção e a gestão da própria identidade, através de estratégias que são categorizadas em três níveis (visual self: "Watch me and know me by my friends'; cultural self, que decorre da partilha dos gostos e preferências: 'See what I like/do/ read/listen to' e a terceira estratégia, narrative self, em que se abordam características da personalidade: 'About Me' e que corresponde à estratégia menos utilizada. (Zhao, S. Grasmunck, S. Martin, J., 2008). No caso específico da rede social Facebook, de onde se extraiu o corpus deste trabalho, de acordo com Miller (2008: 393-395), que aborda o conceito de tecnologias fáticas, distintamente de outros meios eletrónicos de comunicação, o objetivo primordial dos participantes nesta rede é a mera comunicação com a finalidade de estabelecer ou manter relações sociais. Estamos cientes de que, embora as interações tenham primordialmente o objetivo de estabelecer e manter relações, não podemos deixar de considerar que, por meio delas, ou para que elas se fortaleçam, entram em jogo as estratégias de construção 
da identidade, especialmente a partilha de gostos e visibilidade pessoal para os amigos, além de "narrative self", por meio da exposição de experiências pessoais que expressam implicitamente peculiaridades de personalidade dos usuários.

De acordo com Georges (2010), as formas de comunicação via Web reconfiguraram as relações sociais e possibilitaram o surgimento de novas formas de pensamento. As interrelações que se constroem na rede, segundo a autora, transformaram-se no decorrer de sua existência; as pessoas assumem posições mais pragmáticas, focadas no desejo de manifestar sua existência. A pesquisadora destaca ainda o papel das interações escritas, sobre as quais se definem as imagens dos utilizadores, contexto no qual emerge um processo de argumentação da identidade pela tecnologia. Além disso, de acordo com a mesma autora, o virtual autoriza experiências inéditas e liberta a imaginação, fazendo surgir novas exigências, uma forma diferente de vivenciar o presente. O facto é que, na rede Facebook, os interlocutores estão constantemente a construir sua identidade, uma imagem idealizada de si, fundada também na construção da imagem do outro (Terkoufari, 2008). Ao tecer comentários valorizadores relativamente ao outro, valoriza-se a própria face.

A interface do Facebook ordena as contribuições iniciativas, surgindo, em primeiro lugar, as mais recentes. Por outro lado, os comentários reativos surgem hierarquizados relativamente às contribuições iniciativas. Subscrevemos a categorização de Celik (2015) que resumimos de seguida: a "contribuição isolada" consiste em uma contribuição iniciativa colocada na rede e permanece de forma isolada, isto é, não é diretamente respondida ou comentada por ninguém; A “troca dialogal”, como o próprio nome estabelece, é constituída por uma contribuição iniciativa seguida de uma contribuição reativa. Cumpre esclarecer que essa troca pode prolongar-se, mas resta confinada a dois interlocutors; Já a "troca polilogal" diz respeito a uma interação na qual participam pelo menos três interlocutores distintos, é constituída por uma contribuição iniciativa, seguida de múltiplos comentários reativos. Por fim, e como reação reativa mínima, encontramos amiúde o comentário "Gosto"/"Like", uma das formas mais frequentes de interação. Essa contribuição é considerada o grau zero da interação, mantendo e reforçando o elo de ligação, a conivência entre os interlocutores, encerrando dois sentidos: por um lado, o de uma apreciação favorável ao da contribuição iniciativa; e, concomitantemente, o registo de uma conivência, de um agradecimento. É no contexto das 
trocas dialogais e polilogais que situamos nosso estudo, uma vez que nosso interesse recai sobre os comentários elogiativos, o que nos conduz ao estudo da cortesia valorizadora.

Sem passar em revista os estudos sobre cortesia, não poderemos deixar de citar como ponto de partida os trabalhos de Goffman (1971 [1959], 1970 [1967]), seguidos dos contributos de Lakoff (1973), Leech (1983) e Brown y Levinson (1978, 1987) que estabelecem a distinção entre cortesia positiva (estratégias de valorização da imagem) e cortesia negativa (estratégias de evitação da ameaça potencial de alguns atos).

Outras das propostas enriquecedoras é a de Kerbrat-Orecchioni (2004: 43) que inova relativamente aos fundadores, ao sublinhar que a cortesia para além de mitigar ameaças consiste também e sobretudo em produzir anti-ameaças, atos valorizadores da imagem positiva do interlocutor, face flattering acts (FFA), atos valorizadores da face. Para Kerbrat-Orecchioni, nas interações produz-se sempre um jogo equilibrado entre atos ameaçadores da face, face threatning acts (FTAs) e FFAs e sublinha-se a tendência de que em situações não conflituosas, os FTAs tendem a ser amplamente suavizados, ao passo que os FFAs tendem a ser reforçados (2004: 45). Esta ideia é, de resto, corroborada por Bayraktaroglu (1991) que designa este tipo de atos como "Face Boosting Acts" (FBAs) "atos levantadores/aumentadores da imagem", que têm como objetivo satisfazer as necessidades da imagem do locutor ou do interlocutor. Por seu turno, Sifianou (1995), bem como como Terkourafi (2005), optam pela designação Face Enhancing Acts (FEAs) "atos realçadores da imagem” .

Privilegiámos e adotámos a designação "cortesia valorizadora" (em oposição à de cortesia mitigadora), que é recorrente nos estudos hispânicos sobre cortesia, e é usada, nomeadamente por Albelda (2004, 2005) e Hernandez Flores (2004: 101).

Circunscrevendo o conceito de cortesia valorizadora, adotaremos os pressupostos de Bernal (2007) e a designação de Barros García (2011) que a define do seguinte modo:

[...] actividad cortés enfocada hacia la producción de algún tipo de beneficio para la imagen del interlocutor, beneficio que suele tener consecuencias positivas para la imagen del propio hablante y que contribuye a la creación de lazos interpersonales más sólidos entre los interlocutores y al aumento de la eficacia comunicativa (2011: 136). 
Para a classificação deste tipo de atos, na nossa análise, tivemos em consideração a classificação de Haverkate (1994) de atos expressivos, cujo objetivo ilocutório consiste na expressão de um estado psicológico do locutor relativamente ao estado de coisas que está especificado no conteúdo proposicional do enunciado.

"Expressives are attempts to express (or make external) the speaker's inner psychological state. In speech act terms, they are attempts to express a particular attitude represented by the propositional content of the utterance. Hence, the sincerity condition for all expressives is the intended expression of some internal psychological state. The propositional content and preparatory conditions vary over speech act types. (Holtgraves 2005: 2032)

Os atos expressivos, como afirma Palrilha, "expressam emoções, sentimentos, avaliações, juízos de valor ou desejos: essa é a intenção que subjaz à elocução”. (Palrilha 2009: 48)

Socialmente, o ato de elogiar consiste em regozijar-se com o bem de outrem. Também pode ter a função de encorajar o destinatário, funcionando como estímulo positivo, ou como reforço da imagem do destinatário e, consequentemente, das relações entre os interlocutores.

Albelda Marco (2007: 203), por sua vez, considera ser um tipo de interação ao serviço da "cortesia valorizante", podendo manifestar-se de forma direta, mediante a realização de atos de reforço da imagem, ou indireta, apoiando o dito de um terceiro interlocutor, com meras manifestações de acordo (pró-argumentos, ratificações)

Este ato é considerado altruístico, na medida em que felicitar/elogiar é um gesto cordial cortês que fortalece os laços entre as pessoas e contribui para a construção da sociabilidade, pelo que tem fundamentalmente como objetivo ilocutório criar ou manter um ambiente de cortesia.

\section{Atos de fala expressivos: felicitações, os elogios e outros atos laudatórios}

Qualquer ato de linguagem implica a construção de uma imagem de si no discurso e essa imagem depende diretamente da influência que o locutor deseja exercer no seu interlocutor no momento da enunciação. 
Trata-se de um ethos que se constrói no âmbito da atividade enunciativa e que se faz notar através do seu discurso:

“a construção da imagem do enunciador diz respeito às escolhas linguísticas feitas por ele, que revelam pistas acerca de si durante o processo discursivo" (Maingueneau, 2005:70)

O conceito de ethos (seguindo as propostas de Maingueneau (2005) e de Ruth Amossy (2010)) é aqui entendido como a imagem do locutor que se constrói no discurso e pelo discurso, ou seja, a imagem do enunciador criada no momento da enunciação, na instância do discurso, imagem essa que mobiliza implícitos de uma relação de interação com os coenunciadores que detêm representações culturais estereotipadas e imagens pré-estabelecidas.

O ethos está, pois, em estreita articulação com a cena enunciativa. Exprime-se através da enunciação elocutiva:

«...s'exprime à l'aide des pronoms personnels de première personne, accompagnés de verbes de modalité, d'adverbes et de qualificatifs qui révèlent l'implication de l'orateur et décrivent son point de vue personnel.» (Charaudeau, 2005: 135)

A imagem dos enunciadores nas mensagens do Facebook faz transparecer um ethos que adota estratégias de valorização sua própria face (na terminologia de Brown \& Levinson), que o credibilizem e que o façam ser apreciado (e inclusivamente invejado) pelos demais.

Komesu (2005: 198), a propósito de outra forma de CMC, advoga que este modo de enunciação assenta na "publicização de si", ou seja, o objetivo principal do enunciador é ser visto, e, por isso, a construção do ethos exibicionista.

O jogo do desvendamento, o processo de ir revelando, a par e passo, aspetos da esfera mais pessoal ou íntima cria uma espécie de encanto mágico e explora a curiosidade alheia. Segundo Marichal (2012: 34) limitamo-nos a fazer aquilo para que fomos biologicamente programados: partilhar. 


\section{Metodologia, estabelecimento das categorias de análise e constituição do corpus}

Face à imensidão de interações na rede social e à sua volatilidade, a noção de corpus no estudo das interações escritas em linha, ganha uma nova dimensão. Conforme expusemos no início deste trabalho, metodologicamente, é mister considerar instrumentos da Análise da Comunicação Mediada por Computador (ACMC), tais como os defendidos por Herring (2004), ou seja, as análises devem basear-se em dados empíricos, produzidos de forma espontânea e coletados online pelo pesquisador. O comentário da rede social Facebook oferece dados dessa natureza por configurar um espaço discursivo, social, público voltado para a comunicação e para o estabelecimento de relações sociais e sua manutenção (Miller, 2008), permitindo também a construção e a gestão da própria identidade. Nesse sentido os frequentadores/utilizadores do Facebook encontram nesse contexto um espaço aberto para estabelecer, manter ou reforçar as relações interpessoais, e reforçar a sua imagem; para tanto, no caso dos exemplos que compõem nosso corpus de análise, recorrem a estratégias de cortesia valorizadora.

Embora este não seja o foco do presente trabalho, considerando que este estudo pretende expandir-se para a análise comparativa entre o contexto português e brasileiro, o corpus de análise compõe-se de comentários extraídos de páginas do Facebook de dois escritores, sendo um português outro brasileiro. Acreditamos que, futuramente, o aprofundamento deste estudo nos permitirá estabelecer o estudo contrastivo. O corpus português (PT) foi recolhido em setembro de 2016, por ocasião do lançamento de uma tradução da Bíblia pelo escritor e professor universitário português, Frederico Lourenço (doravante FL), que tem grande visibilidade na rede, pois a sua página não é restringida a determinadas pessoas, pelo que podemos observar comentários quer de amigos, quer de desconhecidos, o que impede de traçar o perfil sociolinguístico dos intervenientes, não sendo porém esse o objetivo desta análise. Por sua vez, o corpus brasileiro (BR) foi recolhido em abril de 2016, da página Facebook do poeta brasileiro Bráulio Bessa (doravante BB), autor de literatura de cordel, e constitui-se de comentários a partir de seu post de 24 de abril de 2016. Foram recolhidos ao todo 178 comentários dos quais selecionamos alguns exemplos para a exposição das análises neste trabalho.

Segundo Goffman (1993), expressamo-nos de forma diferente perante os nossos interlocutores e segundo as expectativas morais e sociais subjacentes ao que o contexto situacional projeta e, neste sentido, a existência de papéis sociais é uma das estratégias 
fundamentais que orientam o nosso comportamento verbal. A observação dos 178 comentários permitiu-nos, por conseguinte, elencar seis categorias de atos valorizadores, que expomos brevemente:

a. Felicitações - trata-se de comentários reativos que expressam uma simples felicitação dirigida ao produtor da contribuição iniciativa ou ao produtor do post de Facebook que está em foco.

b. Elogios diretos focados no destinatário - trata-se de comentários reativos que veiculam a expressão de um elogio ao autor da contribuição iniciativa.

c. Elogios diretos focados no objeto - trata-se de comentários reativos que expressam um elogio ao tema ou ao objeto em discussão no conjunto de contribuições.

d. Elogios indiretos - trata-se do recurso a outros atos expressivos, como, por exemplo, atos de agradecimento, por meio do quais o produtor do comentário reativo expressa um ato valorizador do produtor da contribuição iniciativa.

e. Elogios indiretos coconstruídos - trata-se de elogios ao utilizador detentor da página ou produtor da contribuição iniciativa expresso de forma indireta, por meio da exposição de um estado ou sentimento que diz respeito ao próprio produtor do comentário reativo.

f. Elogios indiretos desviantes - trata-se de situações em que o participante, na troca polilogal, com seu comentário reativo, utiliza um espaço de discussão no qual se serve do elogio como meio para introduzir outro tema de seu interesse, mas desviante relativamente ao tema em discussão.

Cumpre destacar que o estabelecimento dessas categorias não ocorreu de forma fácil; ao contrário, dada a variedade dos comentários, é bastante complexo o trabalho de categorização dos fenómenos, o que nos indica a necessidade de ampliação do corpus para futuros trabalhos.

Para a apresentação dos exemplos, foram omitidos os nomes dos participantes e mantidas suas iniciais e a data do comentário. 


\section{Atos valorizadores em comentários elogiativos no Facebook: análise das estratégias discursivas}

Nesta secção, apresentamos a análise ilustrativa de exemplos extraídos dos corpora.

A primeira categoria de ato elogiativo constitui a felicitação simples, como podemos observar nos três exemplos que seguem, sendo dois do corpus português e o último do corpus brasileiro.

(1) (PE) M. C. Mais uma vez, Parabéns FL, que nunca serão demais. Beijinhos.

Gosto $\cdot$ Responder $\cdot 1 \cdot 24 / 9$ às 9:54

(2) (PE) C. C. Muitos parabéns ! Casa cheia! Alguns mesmo em pé ! Não admira!!!

Gosto $\cdot$ Responder $\cdot 1 \cdot 24 / 9$ às 10:06

(3) (PB) E. S. Fico emocionada !!! Parabéns belíssimo Cordel!

A forma mais clara do ato de felicitar é dizer "Parabéns", conforme encontramos nos três exemplos expostos. Ao comentar "parabéns", o participante manifesta claramente seu elogio, enaltecendo o interlocutor que está no foco dos comentários. Trata-se sobretudo de uma manifestação económica do ponto de vista linguístico, configurando o grau zero da felicitação. Importa, contudo, anotar que todos os três comentários que contêm parabéns não se limitam à única palavra do elogio direto. Pode-se assim inferir que a preocupação maior não era com a economia de texto, mas simplesmente com a expressão mais direta do elogio.

Muitos intervenientes não recorrem ao elogio simples, dando preferência a elogios diretos focados no destinatário, no caso de nosso corpus, os dois escritores.

(4) (PE) J. S. Estive presente. A tradução da Bíblia por FL é um acontecimento notável nacional e internacionalmente. Para além da erudição, FL pensa muito bem é é muitíssimo claro na explicitação do seu método de trabalho. Uma beleza este encontro! Gosto $\cdot$ Responder $\cdot 4 \cdot 23 / 9$ às $7: 24$ 
(5) (PB) F. G. M. BB, sou fã da sua arte e por mts vezes me emocionei te ouvindo! Vc é maravilhoso! 22/4 às 15:54

Em (4), o participante, em seu comentário, enaltece o escritor português, afirmando que ele pensa muito bem e é muitíssimo claro na explicitação do seu método de trabalho. Ao destacar qualidades positivas do produtor da contribuição iniciativa, elogia-o diretamente. Em (5), também encontramos um elogio do destinatário, com Vc é maravilhoso!. Trata-se de uma manifestação mais subjetivamente marcada pelo adjetivo "maravilhoso" e pelo emprego do ponto de exclamação, denotando estado emocionado do interveniente. Além disso, podemos observar que em (4), o produtor procura manter maior distanciamento, com o emprego da terceira pessoa para referir o destinatário, enquanto em (5) encontramos o pronome de tratamento "você" que, discursivamente, indica o interlocutor, ou seja, no português do Brasil é uma forma interlocutiva de segunda pessoa, expressando maior envolvimento do participante, maior proximidade com o produtor da contribuição iniciativa.

Há situações nas quais em vez de elogiar o destinatário, se elogia o objeto em apreço, o tema do post, como é o caso do lançamento da tradução da Bíblia por FL:

(6) (PE) Y. C. Edição lindíssima, já comecei a ler.

24/9 às 13:40

Em (6), o comentário refere a própria edição da tradução produzida pelo escritor português (Edição lindíssima). O elogio recai sobre o produto. Evidentemente, ao elogiar o produto, elogia-se igualmente o produtor. Anote-se, neste exemplo, a brevidade da mensagem, que conjuga o elogio sobre o objeto/produto e o comentário pessoal, com a marca de primeira pessoa, que é recorrente nas produções discursivas nas redes sociais, tal como já foi demonstrado em Seara 2015. De forma similar em (7), o utilizador elogia o produto, mais especificamente o poema que constitui a contribuição iniciativa do poeta de cordel brasileiro (Lindo... Real... Verdadeiro e intenso esse Cordel...). O elogio recai, portanto, sobre a própria contribuição do poeta na rede Facebook, mas, assim como no caso anterior, (6), estende-se ao produtor. 
(7) (PB) D. C. K. Lindo... Real... Verdadeiro e intenso esse Cordel... Amo minha profissão. Amo Ser Professora e até o fim vou sempre acreditar na Força de um professor (a). Valeu BB...

\section{$22 / 4$ às 14:54}

Encontramos casos em que os participantes, em vez de elogiarem o destinatário ou o produto em foco, no comentário que constitui a contribuição iniciativa, recorrem a outro ato expressivo para expressar o seu elogio, manifestando, dessa forma, a cortesia valorizadora. É o que observamos em (8) e (9) a seguir:

(8) (PE) M. E. A. Obrigada, pela gentileza, pela elegância, pela delicadeza, pela humildade, pela simpatia a que habituou todos os que tratam consigo. Só os Grandes o conseguem. Um grande abraço de agradecimento

Gosto $\cdot$ Responder $\cdot 6 \cdot 24 / 9$ às 10:11

(9) (PB) A. A. Obrigada por enaltecer os professores, infelizmente uma categoria esquecida e menosprezada pelos governantes.

Eu também acredito na sua ascensão enquanto cordelista, levando o nosso nordeste ao topo do mundo.

Parabéns - BB!

Curtir $\cdot$ Responder $\cdot 30$ de abril às 13:48

Nas duas contribuições reativas apresentadas em (8) e (9), os participantes utilizam o ato de agradecimento para manifestar a cortesia valorizadora. Trata-se de uma forma indireta de elogio, pois o agradecimento expressa a aprovação, mais do que isso, a valorização do objeto pelo qual se agradece. Em (8), o interveniente, ao agradecer, expressa juntamente elogios ao escritor português, caracterizando-o por ser dotado de gentileza, elegância, delicadeza, humildade, simpatia. Sobre todas essas qualidades de FF recai o agradecimento do participante; o agradecimento assume, assim, valor de elogio. Em (9), o participante, em seu comentário, agradece pela ação do poeta brasileiro. $\mathrm{O}$ agradecimento pela partilha do poema postado no Facebook constitui igualmente uma forma de enaltecer o próprio poeta. 
Importa sublinhar a ocorrência de um fenómeno, bastante recorrente na rede social, que é o elogio construído por meio da expressão de um sentimento ou de uma sensação que diz respeito ao próprio produtor da contribuição reativa, em vez de focalizar o destinatário alvo do elogio e da cortesia valorizadora.

(10) (PE) M C L. Fiquei muito feliz de vos encontrar esta manhã. É um privilégio e um luxo ter um fantástico intelectual, generoso, simples e delicado a trabalhar no nosso local de trabalho! Esta manhã apeteceu-me dizer que era uma obrigação de todos os colegas do Frederico estarem aí, para lhe agradecer o quanto ele nos estimula; às vezes, ilumina.

22/9 às 19:38

Em (10), o participante manifesta seu estado emocional diante do lançamento da tradução, tema da discussão (Fiquei muito feliz); além de manifestar um estado emocional, expõe sua vontade (Esta manhã apeteceu-me) e a avaliação do facto do ponto de vista da experiência pessoal (um privilégio e um luxo). Todas essas manifestações cumprem um dupla função: indicam o estado de espírito do participante que formula seu comentário e, simultaneamente, enaltecem o destinatário, ou seja, o responsável pela contribuição iniciativa.

Também em (11), o participante manifesta um gosto (comecei gostar de literatura de cordel) e tal preferência se transforma em elogio ao poeta brasileiro:

(11) (PB) A G. de A. Desde adolescente comecei gostar de literatura de cordel, mas depois que o BB começou a vir no programa da Fátima, eu passei a gostar muito mais. Curtir $\cdot$ Responder

$22 / 4$ às $21: 34$

O participante manifesta uma experiência pessoal, a de que conheceu o poeta $\mathrm{BB}$, para, com base nela, expor um sentimento seu (passei a gostar muito mais). Podemos afirmar que, com base nesse sentimento, isto é, gostar mais de literatura de cordel devido ao fato de conhecer os poemas de $\mathrm{BB}$, o interveniente expressa indiretamente um elogio ao próprio poeta. Nestes exemplos podemos constatar, mais uma vez, a presença das marcas do "eu" . São sobretudo 
exteriorizadas as reações auto-centradas, despoletadas por algo que alguém faz. O mesmo acontece em (12):

(12) (PB) F L Que coisa linda, BB! Senti-me honrada e fortalecida com suas palavras... Quisera todos tivessem essa sensibilidade, e como vc, acreditasse, valorizasse e apoiasse o professor!

Sou sua fã !

Curtir $\cdot$ Responder

$23 / 4$ as $11: 25$

Por seu turno, em (12), ao manifestar sentir-se honrada de fortalecida com as palavras do poeta, a participante indiretamente elogia o poema e, por contiguidade, o poeta. Com efeito, somente provoca honra e sensação de fortalecimento algo que é bom e, portanto, é passível de elogio. Devemos considerar, conforme já expusemos anteriormente neste trabalho, que os usuários da rede Facebook, constroem sua identidade o tempo todo; e essa identidade é sobretudo pautada no positivo, buscado uma imagem idealizada. Assim, ao expor seus sentimentos positivos relativos aos outros utilizadores ou relativos aos atos que eles realizam, os usuários não apenas valorizam a própria imagem por mostrar sentimentos positivos, mas também elogiam o outro com quem interagem e, de forma análoga, ao elogiarem o destinatário, também se apoiam nesse elogio para construir uma imagem de si também positiva. Assim, ao tecer comentários valorizadores relativamente ao outro, valoriza-se a própria face.

É preciso considerar que nem todos as contribuições na rede Facebook se confinam à temática em discussão. Há intervenientes que se apropriam de determinado tema em discussão para, a partir dele, introduzir uma outra temática de seu interesse. Encontramos casos em que tal ação se dá por meio de um elogio indireto. Esses casos constituem a categoria que designámos "elogios indiretos desviantes".

(13) (PE) M. B. S. Trabalhos como este levam longos anos a fazer, enquanto a sociedade perde tempo com histórias mediocres daqueles que enterram o País todos os dias, na Torre do Tombo dezenas de investigadores mal conseguem sobreviver, muito menos ter 
apoios para seus dignos trabalhos. Parabéns continue a transmitir cultura $e$ conhecimento.

Gosto $\cdot$ Responder $\cdot 2 \cdot 26 / 9$ às $12: 21$

(14) (PB) A. A. Obrigada por enaltecer os professores, infelizmente uma categoria esquecida e menosprezada pelos governantes.

Eu também acredito na sua ascensão enquanto cordelista, levando o nosso nordeste ao topo do mundo.

Parabéns -Bráulio Bessa!

Curtir $\cdot$ Responder $\cdot 30 / 4$ às 13:48

Em (13), o participante expressa um elogio indireto escrevendo em seu comentário que "Trabalhos como este levam longos anos a fazer". O comentário sobre o extenso tempo que subjaz à excelência do trabalho do escritor/tradutor português traz implícito um elogio que se concretiza na parte derradeira da mensagem com a expressão direta da felicitação "Parabéns". O sujeito aproveita-se, entretanto, da sua contribuição reativa ao lançamento da tradução da Bíblia para manifestar a sua crítica à falta de apoio a outros investigadores e à perda de tempo da sociedade com "histórias medíocres". A maior parte da extensão da contribuição desse interveniente é direcionada para a crítica, o que nos permite inferir que o seu objetivo, de facto, não era elogiar o escritor português ou a sua obra, mas, ao contrário, o elogio mascara outra estratégia para abordar outro tema de seu interesse. Tal ato constitui um elogio indireto desviante, pois ocorre um desvio do tema relativamente à contribuição iniciativa.

A mesma estratégia de emoldurar o ato desviante de elogios, apresentados no início e no fim da contribuição é utilizada em (14). A contribuição (14) apresenta inicialmente um agradecimento (“Obrigada por enaltecer os professores”) que, por sua vez, introduz a temática desviante. $\mathrm{O}$ poema tem como tema a profissão de professor. O usuário recorre a esse tema para criticar a desvalorização da classe pelo governo ("infelizmente uma categoria esquecida e menosprezada pelos governantes”), facto que não diz respeito ao poema nem ao poeta, constituindo um comentário desviante.

Finalmente, convoca-se um exemplo bastante significativo do corpus, que ilustra a extensão dos atos expressivos e seu caráter elogiativo nos comentários: 
(15) (PE) F. S. Já há reação oficial de Deus? :D

23/9 às 8:04

Em (15), temos um elogio indireto, expresso através de uma pergunta retórica, que configura uma "cobrança" de contribuição de outro utilizador. O comentário é pertinente e muito expressivo no contexto da tradução da Bíblia, por motivo óbvio, pois Deus é o cerne da obra religiosa em apreço. A manifestação da expetativa de uma "reação oficial de Deus" constitui o elogio máximo que se pode atribuir ao escritor, afinal, uma reação de Deus, como entidade suprema.

\section{Considerações finais}

Ao iniciarmos este trabalho, traçamos como objetivo investigar as estratégias linguístico-discursivas que estão na base da cortesia valorizadora presente nos comentários elogiativos, a fim de verificar de que forma o espaço discursivo comentário no Facebook permite a construção e a gestão da própria identidade e do outro. Por meio da análise de um corpus composto de 178 comentários na rede social coletados em páginas de dois escritores, pudemos constatar que há muitas formas de manifestação de elogios, o que nos permitiu estabelecer seis categorias de elogios. Importa sublinhar que o estabelecimento de tais categorias exigiu a demarcação de critérios específicos, face à variedade de manifestações e à diversidade das estratégias que complexificaram esse trabalho de categorização. Conforme destacamos no desenvolvimento do trabalho, as dificuldades enfrentadas indiciam a necessidade de ampliação do corpus para a prossecução da investigação.

Todavia, as análises apresentas neste estudo permitem-nos já tecer algumas considerações. As estratégias linguístico-discursivas observadas na realização de atos de fala expressivos, nomeadamente comentários elogiosos, estão indubitavelmente a serviço da cortesia valorizadora. Esta, por sua vez, cumpre uma ampla função na construção das identidades, tanto da identidade do destinatário que se deseja enaltecer, quanto, e talvez, mais ainda, na construção da identidade do próprio interveniente, produtor da contribuição. Concluímos que os interlocutores, ao tecerem comentários valorizadores por meio de elogios aos destinatários, seja a ele diretamente, por meio de felicitações, de elogios diretos focados no destinatário ou no objeto da discussão, seja indiretamente, por meio de elogios indiretos 
coconstruídos e, ainda através de elogios desviantes, visando abordar outros temas de interesse próprio, constroem recorrentemente a própria imagem na rede social, identidade essa que, assim como a dos seus destinatários, busca a própria valorização. Podemos, assim, afirmar que ao tecer comentários valorizadores relativamente ao outro, o utilizador se valoriza a si próprio, construindo sua identidade, uma imagem idealizada positiva de si, fundada na construção da imagem positiva do outro.

\section{Referências}

Alberlda, M. (2004) "Cortesía en diferentes situaciones comunicativas: la conversación coloquial y la entrevista sociológica informal”, Bravo, D. e A. Briz (eds.): Pragmática sociocultural. Estudios sobre el discurso de cortesía en español, Barcelona: Ariel, pp. 109-134.

Amossy, R. (2010) La présentation de soi. Ethos et identité verbale. Paris: Presses Universitaires de France.

Anis, J. (1998) Texte et ordinateur: L'écriture réinventée. Paris, Bruxelles: De Boeck Université.

Anis, J.(dir.) (1999) Internet, communication et langue française. Paris: Hermès.

Araújo Carreira, M.H. (1997) Modalisation linguistique en situation d'interlocution: proxémique verbale et modalités en portugais. Louvain- Paris: Peeters.

Bayraktaroglu, A. (1991) "Politeness and interactional imbalance", International Journal of the Sociology of Language, 92, pp. 5- 34.

Barros García, M. J. (2011) La cortesía valorizadora en la conversación coloquial española: estudio pragmalingüístico. Tesis Doctoral, Granada: Universidad de Granada.

Barros García, M. J. (2012) "Cumplidos y ofrecimientos: acti vidades de cortesía valorizadora en la conversación coloquial es pañola”, Escamilla Morales, J. y G. Henry Vega (Eds.): Miradas multidisciplinares a fenómenos de cortesía en el mundo hispánico, Universidad del Atlántico e Programa Edice. pp. 108- 143.

Bernal, M. (2007) Categorización sociopragmática de la cortesía y la descortesía. Un estudio de la conversación coloquial española. Estocolmo: Universidad de Estocolmo. 
Bernal, M. (2005) "Hacia una categorización sociopragmática de la cortesía, la descortesía y la anti- cortesía. El caso de conversacio- nes españolas de registro colo- quial”, Bravo, D. (Ed.): Estudios de la (des)cortesía en español. Categorías conceptuales y aplicaciones a corpora orales y escritos. Estocolmo-Buenos Aires: Dunken, pp. 365-398.

Bravo, D. e Briz, A. (Eds.) (2004) Pragmática sociocultural. Estudios sobre el discurso de cortesía en español. Barcelona: Ariel.

Brown, P. \& Levinson, S. (1987) Politeness: Some Universals in Language Usage. Cambridge: Cambridge University Press.

Brown, P. \& Levinson S. (1978) “Universals in Language Use: Politeness Phenomena”, Goody, E. (Ed.): Questions and Politeness. Strategies in Social Interaction. Cambridge: Cambridge University Press, pp. 56-289.

Charaudeau, P. (2005) Le Discours politique : les masques du pouvoir. Paris: Vuibert.

Crystal, D. (2006) Language and the Internet (2nd edition) Cambridge: University Press.

Crystal, D. (2011) Internet Linguistics: A Student Guide. New York: Routledge.

Celik, C. (2015) Commenter en ligne: affrontement polémique et impolitesse. In Ulla Tuomarla U., Tiittula L., Sairio A., Isosävi J., Paloheimo M., (dir.) Du malentendu à la violence verbale, Mémoires de la Société Néophilologique de Helsinki. Helsinki: Société Néophilologique, pp.45-58.

Develotte, C. (2006) Décrire l'espace d'exposition discursive dans un campus numérique. Le Français dans le monde. Recherches et applications (numéro spécial). 88-100. http://halshs.archives-ouvertes.fr/docs/00/15/18/51/PDF/expositiondiscursive.pdf [acedido em outubro de 2016]

Develotte, C. Kern R. e Lamy, M.-N. (dir.) (2011) Décrire la conversation en ligne. Lyon: ENS éditions.

Emerit-Bibié L. (2015) Description du discours numérique. Étude des bouleversements linguistiques du web 2.0 au travers de l'exemple des souhaits d'anniversaire sur Facebook, Thèse de doctorat, Bordeaux: Université Bordeaux 3.

Georges, F. (2010) Identités virtuelles les profils utilisateur du web 2.0. Paris: Éditions Questions Théoriques.

Goffman, E. (1959) The presentation of the Self in Everyday Life, NY: Doubleday. 
Goffman, E. (1967) Interaction ritual: Essays on Face-to-Face Behavior. NY: DoubledayAnchor.

Haverkate, H. (1993) “Acerca de los actos de habla expresivos y comisivos en español”, in Aproximaciones pragmalingüísticas al español. Amsterdam: Editoral de la Universidad de Amsterdan, pp. 149- 80.

Haverkate, H. (1994) La cortesía verbal. Estudio pragmalingüístico, Madrid: Gredos.

Hernández-Flores, N. (2004) La cortesía como la búsqueda del equilibrio de la imagen social. In. D Bravo e A. Briz (eds.): Pragmática sociocultural. Estudios sobre el discurso de cortesía en español. Barcelona: Ariel, pp. 95- 108.

Hernández-Flores, N. (2004) La cortesía como la búsqueda del equilibrio de la imagen social. In. D. Bravo e A. Briz (eds.). Pragmática sociocultural. Estudios sobre el discurso de cortesía en español. Barcelona: Ariel, pp. 95- 108.

Herring, S. C. (2004) Computer-Mediated Discourse Analysis: An Approach to Researching Online Behavior. Designing for Virtual Communities in the Service of Learning. Éd. S. Barab, R. Kling et J. H. Gray. NY: Cambridge University Press. 338-376.

Holtgraves, T. E Ashley, A. (2001) Comprehending illocutionary force. In Memory \& Cognition. Muncie, Indiana: Ball State University, pp. 83- 90.

Joinson, A. N. (2008) Looking at, looking up or keeping up with people ?: Motives and use of Facebook. In Proceedings of the SIGCHI Conference on Human Factors in Computing Systems. New York : ACM Press, pp. 1027-1036.

Kerbrat-Orecchioni, C. (2001) Les actes de langage dans le discours. Paris: Nathan.

Kerbrat-Orecchioni, C. (2004) “EE universal la cortesía?”, Bravo, D. e A. Briz (eds.): Pragmática sociocultural. Estudios sobre el discurso de cortesía en español. Barcelona: Ariel, pp. 39- 53.

Komesu, F. (2005) Entre o público e o privado: um jogo enunciativo na constituição do escrevente de blogs da internet. Tese de doutorado, UNICAMP - Universidade Estadual de Campinas, Instituto de Estudos da Linguagem.

Kreutz, C. (2009) The next billion-The rise of social network sites in developing $\square 12$ countries. Web2 forDev.com. Disponível em: www.web2fordev.net/component/content/article/1latestnews/69-social-networks (acesso em setembro de 2016). 
Lampe, C.; Ellison, N.; \& Steinfield, C. (2006) "A Face(book) in the crowd: Social searching vs. social browsing". Proceedings of the 12006 20th Anniversary Conference on Computer Supported Cooperative Work. New York: ACM Press, pp.167-170.

Leech, G. (1983) Principles of Pragmatics. London: Longman.

Leech, G. (2007) "Politeness: Is there an East-West divide?". Journal of Politeness Research, 3, pp. 167-206.

Maingueneau, D. (2005) "Ethos, cenografia, incorporação". In Amossy, R. (org.). Imagens de si no discurso: a construção do ethos. São Paulo: Contexto.

Marichal, J. (2012) Facebook Democracy. The architecture of Disclosure and the Threat to Public Life. Surrey: Ashgate Press.

Miller, V. (2008) "New media, networking and phatic culture", Convergence, 14, 4, pp. 387 400.

Moirand, S. (2002) "Exposition discursive”. Dictionnaire d'analyse du discours. P. Charaudeau e D. Maingueneau (dir.). Paris : Seuil.

Palrilha, S. (2009) Contributos para a análise dos atos ilocutórios expressivos em português. Dissertação de mestrado em Linguística e Ensino, Faculdade de Letras da Universidade de Coimbra.

Porto, C. \& Santos, E. (orgs.) Facebook e educação: publicar, curtir, compartilhar (online). Campina Grande: EDUEPB. Disponível em : http//books.scielo.org . Acesso em outubro de 2016.

Recuero, R. (2009) Redes sociais na internet. Porto Alegre: Sulina. Disponível em: http://revistaseletronicas.pucrs.br/ojs/index.php/revistafamecos/article/viewFile/8194/5883>.Acesso em outubro de 2016.

Seara, I.R. (2015) "Marqueurs et stratégies de la confidence dans les fórums et les journaux personnels en ligne”. IN Anamaria Curea, Cristiana Papahagi, Monica Fekete, Sandra Moraru e Veronica Manole (éd.s) Discours en présence. Hommage à Liana POP. Cluj: Presa Universitara Clujeana, pp. 81-92.

Sifianou, M. (1995) "Do we need to be silent to be extremely polite? Silence and FTAs", International Journal of Applied Linguistics, 5 (1), pp. 95-110. 
Terkoufari, M. (2008) Toward a unified theory of politeness, impoliteness and rudeness. In: D. Bousfield; M. A. LOCHER, (eds), Impoliteness in Language. Berlin, NY, Mouton de Gruyter, p.45-74.

Terkourafi, M. (2003) "Beyond the micro-nivel in politeness research", Journal of Politeness Research, 1 (2), pp. 237-262.

Turkle, S. (1995) Life on the screen: Identity in the age of the Internet. NY: Simon \& Schuster.

Vivas Márquez, J. (2014) La cortesía valorizadora en las redes sociales. Análisis de un corpus de publicaciones en Facebook, Pragmalinguística nº 22, pp. 154-172.

Yus, F. (2010) Ciberpragmática 2.0. Nuevos usos del lenguaje en Internet. Barcelona: Ariel.

Zhao, S.; Grasmuck, S.; Martin, J. (2008) Identity construction on Facebook: Digital Identity construction on Facebook: Digital empowerment in anchored relationships. Computers in Human Behavior 24 (2008) 1816-1836. Disponível em: <http:// astro.temple.edu/ bzhao001/Identity\%20Construction\%20 on\%20Facebook.pdf>. Acesso em maio de 2016. 